\title{
Inspeção eletromagnética em cabos de aço usados na indústria de petróleo offshore utilizando técnicas de vazamento de fluxo magnético
}

\section{Electromagnetic Inspection of Wire Rope Used in the Offshore Oil Industry Using Magnetic Flux Leakage Techniques.}

\author{
Tiberio de Moura Neto ${ }^{1 *}$, Rodrigo B. S. de Macedo ${ }^{1}$, Vitor Manoel Silva ${ }^{2}$, Raquel Lima \\ Oliveira $^{1}$
}

\section{RESUMO}

Sistemas de inspeção eletromagnética em cabos de aço ferromagnético utilizam o sensor hall como elemento sensor ao se apropriar do efeito hall para tanto. Sensores hall são transdutores que, quando estão submetidos ao efeito de um campo magnético, variam sua tensão de saída. A forma como essa tensão de saída vai variar depende da relação de aproximação do sensor com o material magnetizado ou em relação a aproximação de um ímã. À medida que há variação na intensidade do fluxo magnético que passa ao longo de uma seção do cabo de aço, em virtude da presença de ímãs permanentes de neodímio, esse sistema é capaz de medir essa variação derivada da perda de uma seção metálica em virtude da presença de pites de corrosão, perda de área metálica devido a corrosão, entalhes, trincas e rompimento de arames das pernas do cabo de aço. Em suma, este estudo tem a intenção de vir em assistência ao segmento da indústria de petróleo offshore e suas plataformas semissubmersíveis que utilizam linhas de ancoragem a partir de cabos de aço. O estudo, por meio de testes, desenvolverá sensores capazes de detectar defeitos em cabos de aço e um projeto mecânico conceitual a partir do solidworks dará formas à essa ferramenta de inspeção.

Palavras-chave: Inspeção Eletromagnética; Cabos de Aço; Sensor Hall.

\section{ABSTRACT}

Electromagnetic inspection systems in ferromagnetic steel cables use the hall sensor as a sensing element when appropriating the hall effect for this purpose. Hall sensors are transducers that, when subjected to the effect of a magnetic field, vary their output voltage. How this output voltage will vary depends on the proximity of the sensor to the magnetized material or on the approach of a magnet. As there is a variation in the intensity of the magnetic flux that passes along a section of the steel cable, due to the presence of permanent neodymium magnets, this system is able to measure this variation derived from the loss of a metallic section due to the presence of pitting corrosion, loss of metallic area due to corrosion, notches, cracks and wire breakage of the wire rope legs. In short, this study intends to come to the assistance of the offshore oil industry segment and its semi-submersible platforms that use anchor lines made from steel cables. The study, through tests, will develop sensors capable of detecting defects in steel cables and a mechanical design will shape this inspection tool.

Keywords: Electromagnetic Inspection; Wire Ropes; Hall Sensor.

\footnotetext{
${ }^{1}$ Universidade Estácio de Sá-Campus Niterói. *E-mail: mouraterceiro@ hotmail.com

${ }^{2}$ Laboratório de Ensaios Não Destrutivos de Materiais Corrosão e Soldagem.
} 


\section{INTRODUÇÃO}

Quando Falamos em plataformas semissubmersíveis de produção, armazenamento e transferência de petróleo, percebe-se nelas, a atuação em reservas de grande profundidade. Por serem flutuantes, essas plataformas e navios utilizam um sistema de ancoragem à base de cabos de aço ou um sistema de posicionamento dinâmico que mantém a plataforma posicionada de forma automatizada.

Essas linhas de ancoragem com corrente e cabos de aço executam um papel de extrema importância à medida que elas são responsáveis por manter o posicionamento das unidades de perfuração e produção.

Essas plataformas são conectadas a cabeça do poço no fundo do leito do oceano por meio de conectores, conhecidos como risers, que são tubos que fazem a interligação entre as plataformas semisubmerssíveis offshore de produção, e um Sistema submarine de perfuração, produção e completamentação. Movimentações além dos limites préestabelecidos em projeto para cada plataforma pode causar danos ambientais, materiais e financeiros em escala mundial.

Por conta da dramaticidade no posicionamento dessas unidades no mar, e levando em consideração os danos causados por um erro nesse posicionamento, as indústrias desse segmento tem investido cada vez mais em recursos humanos e tecnológicos para a inspeção periódica desses cabos de aço que funcionam como linhas de ancoragem.

Técnicas de inspeção de cabos de aço para detecção de defeitos com base em vazamento de linhas de fluxo magnético ou vazamento de fluxo magnético, têm se mostrado, ao longo do tempo, bastante eficazes na detecção de rompimento de arames, perda de área metálica por corrosão e falhas localizadas.

\section{METODOLOGIA}

Esse estudo segue a ideia do conceito de inspeção supramencionada, com a intenção de assistir à indústria de petróleo no tocante à inspeção periódica de cabos de aço utilizados em linhas de ancoragem e demais atividades dentro da indústria do petróleo offshore ao utilizar técnicas dinâmicas de inspeção com a intenção de não parar a produção de petróleo quando do momento da inspeção. 


\subsection{SENSOR HALL}

Sensores hall são transdutores que, quando estão submetidos ao efeito de um campo magnético, varia sua tensão de saída. A forma como esse sinal vai variar depende da relação de aproximação do sensor com o material magnetizado ou em relação a aproximação de um ímã, ou até mesmo em algum tipo de perturbação que pode ter no campo magnético associado ao sensor de efeito hall, como por exemplo, uma fuga de linhas de fluxo de campo magnético (MFL) por conta de um defeito na superfície do material magnetizado.

O sensor hall que se utiliza neste estudo é o A1309KUA-9-T, o sensor foi centralizado de maneira equidistante em relação aos ímãs de neodímio posicionados nas extremidades sobre uma placa de acrílico que tem a função de um espaçador, ou seja, com função de facilitar o translado do sensor experimental ao longo do cabo de aço e manter uma distância constante o sensor e o cabo de aço como mostrado na figura 1 .

Figura 1: Sensor experimental.

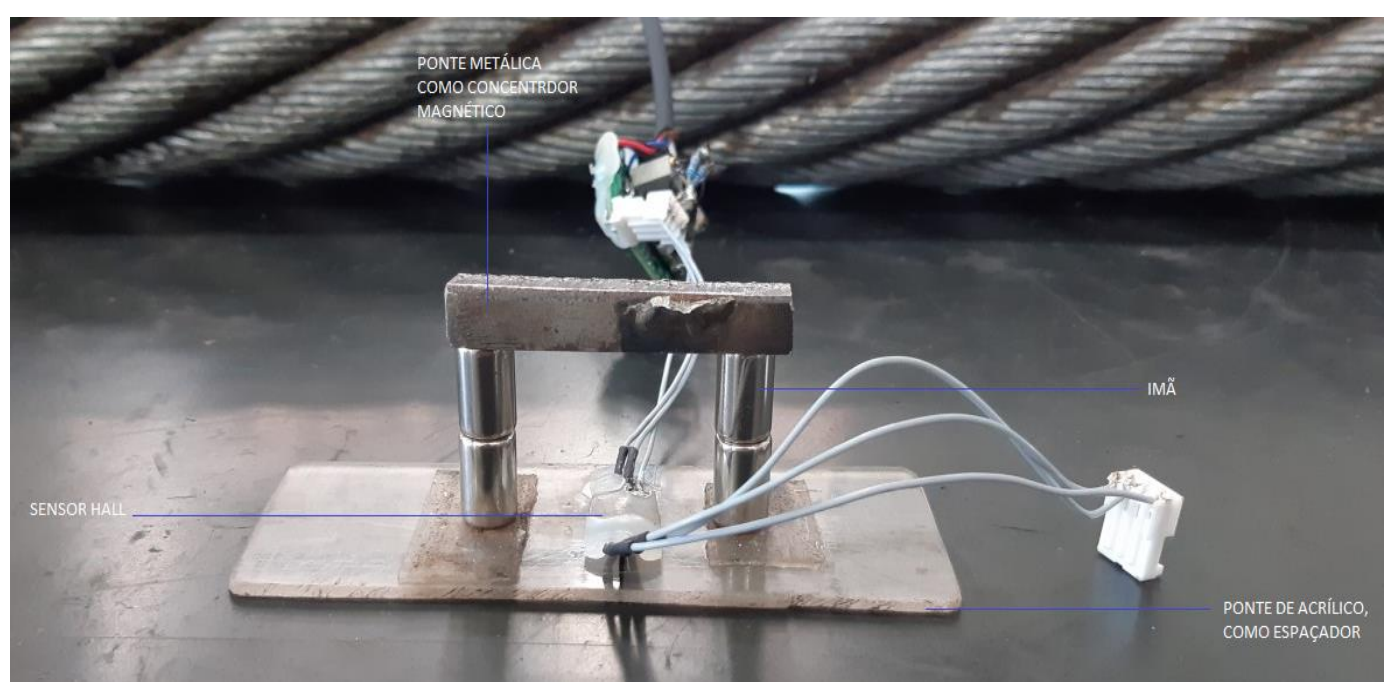

Fonte: Próprio Autor; (2020)

Por se tratar de um estudo que tem a física do magnetismo associada, por condição, o material a ser inspecionado tem de possuir uma alta permeabilidade magnética como é caso dos materiais ferromagnético. O cabo de aço deste estudo é feito a partir de uma liga de aço carbono. 


\subsection{PERMEABILIDADE MAGNÉTICA}

Quando aplica-se um campo magnético $B$ em um material, é induzida uma magnetização $M$ nesse material. A magnetização induzida é diretamente proporcional ao campo magnético aplicado e expressa pela relação $M=X \cdot B$, onde $M$ é a magnetização, $B$ é o campo magnético e $X$ é uma constante de proporcionalidade que é adquirida em laboratório e é especifica de cada material.

Permeabilidade magnética é a capacidade que o material tem de carregar as linhas de campo magnético, ou seja, é a capacidade que o material tem de se magnetizar, um exemplo disso são os materiais magnéticos que apresentam alta permeabilidade magnética.

O material que é alvo desse estudo, o cabo de aço, é feito de uma liga de aço carbono que tem uma alta suscetibilidade magnética. Nesse estudo, gera-se um campo magnético no material a partir de imãs permanentes e se utiliza de sensores de efeito hall para se identificar distorções no campo magnético por uma falta de seção metálica desse material através da tensão de hall que é gerada no sensor que se origina a partir do vazamento de fluxo magnético no material nas regiões de defeito do cabo de aço. A figura 2 mostra como se dá a interação entre o sensor experimental e o cabo de aço.

Figura 2: Sensor e o cabo de aço.

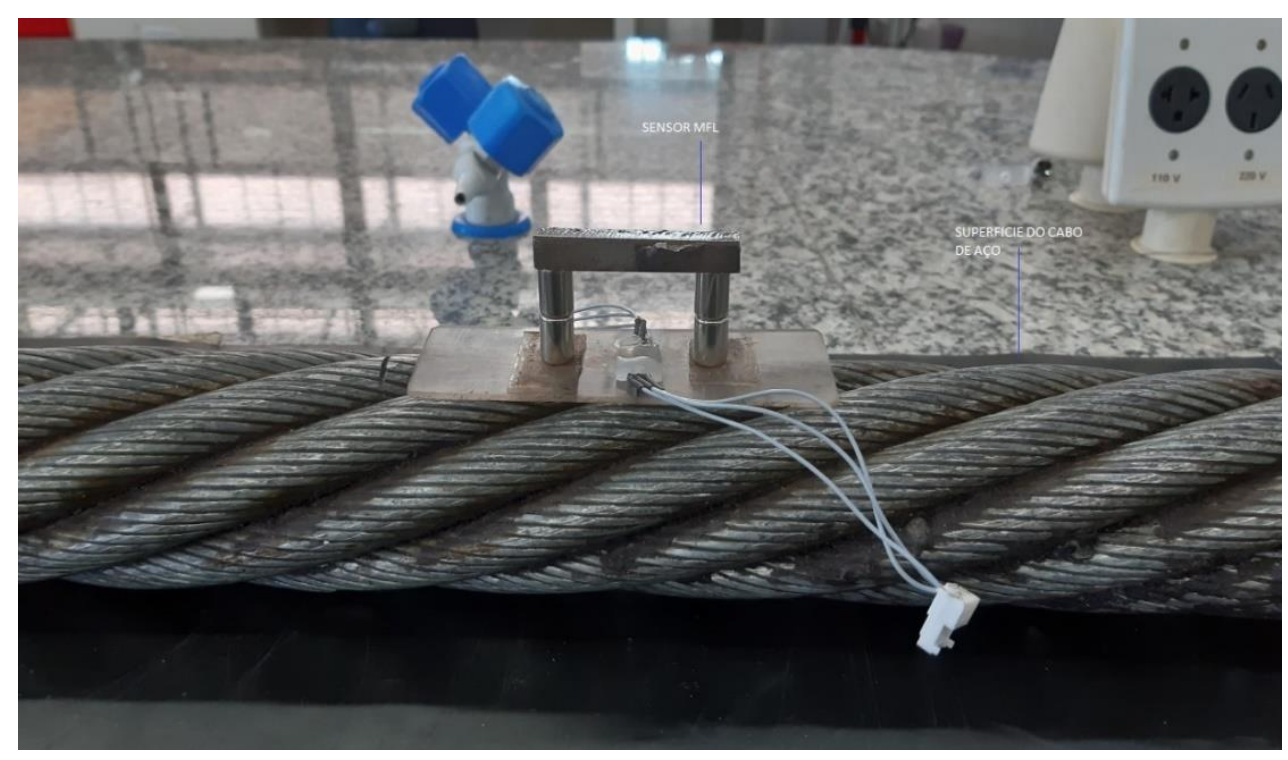

Fonte: Próprio Autor; (2020)

\subsection{TESTES}

Foram utilizados dois cabos de aço como corpos de prova. Usinou-se uma série de defeitos nas pernas do cabo de aço simulando defeitos de entalhe, trinca, rompimento 
e perda de área metálica devido a corrosão nos arames. A idéia dos testes, é transladar o sensor experimental ao longo cabo de aço. Os ímãs de neodímio, posicionados nas extremidades com distância entre centros preestabelecida a partir de ensaios em 48 milímetros (mm). A placa de acrílico foi condicionada em 1,8 milímetros de espessura.

O fluxo magnético percorre todo o sistema do sensor experimental indo de um lado para o outro dos ímãs, passando pela ponte metálica de aço carbono e o cabo de aço. A figura adaptada de Zhang, et al. (2019), mostra bem como funciona o sensor experimental.

Figura 3: Funcionamento do sensor experimental.

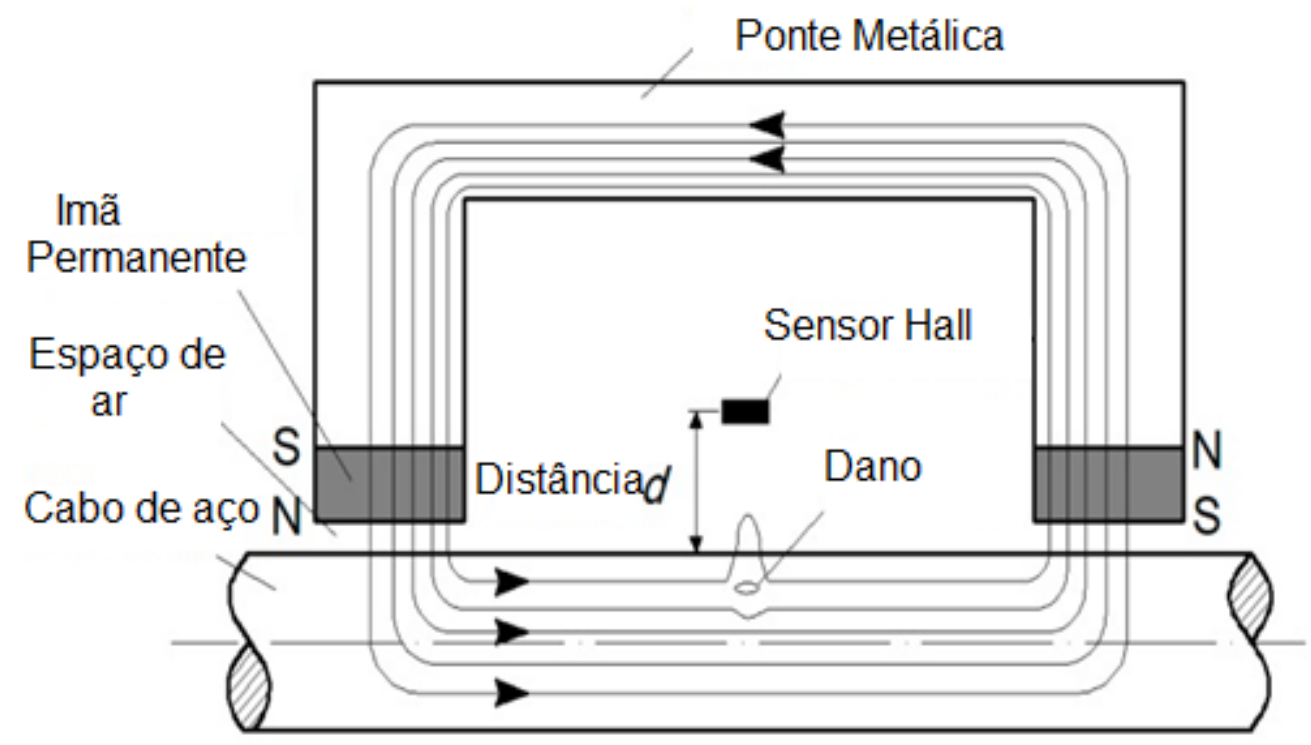

Fonte: Adaptado de ZHANG et al.; (2019).

Pela imagem, percebe-se que a linha de fluxo magnético vaza em direção ao sensor hall, que por sua vez manifesta um sinal de saída conhecido como tensão de hall por estar sob a ação de um campo magnético.

\section{RESULTADOS}

Para tirar o sinal de ruído dos gráficos proveniente da geometria do cabo de aço, utilizou-se o software científico SciLab, que é um programa para computação numérica muito parecido com o MatLab. O tratamento desses dados é desenvolvido a partir da captura dos dados do sensor experimental ao transladar numa região sem defeitos do cabo de aço e coletando os valores de tensão para essa região, posteriormente, coleta-se os 
dados ao transladar esse mesmo sensor na região com defeitos. Naturalmente, a região com defeito apresentará valores de tensão mais elevados em relação a região sem defeito.

Depois de realizado todo esse processo, os valores de tensão da região sem defeito e estabelece como limites $(+\mathrm{X},-\mathrm{X})$ para os quais aqueles valores não representam defeitos. Ao aplicar esses limites dentro do SciLab para as funções dos gráficos e derivando posteriormente, tem-se uma atenuação do sinal de ruído. Importante salientar que a idéia do projeto é que a ferramenta de inspeção herde toda essa programação e mostre os resultados de maneira simultânea.

Nos gráficos de sinais de defeitos, o eixo das abscissas representar a distância percorrida em milímetros $(\mathrm{mm})$ pelo sensor experimentais em relação ao cabo de aço. Já o eixo das ordenadas representa a amplitude do sinal de tensão de hall em milivolt ( $\mathrm{mV}$ ) que caracteriza os defeitos.

A seguir, são dispostas as figuras com os corpos de prova com os defeitos usinados em sua superfície e na sequência, os gráficos tensão $(\mathrm{mV})$ x distância $(\mathrm{mm})$ com os sinais não tratados e tratados.

Figura 4: corpo de prova 1.

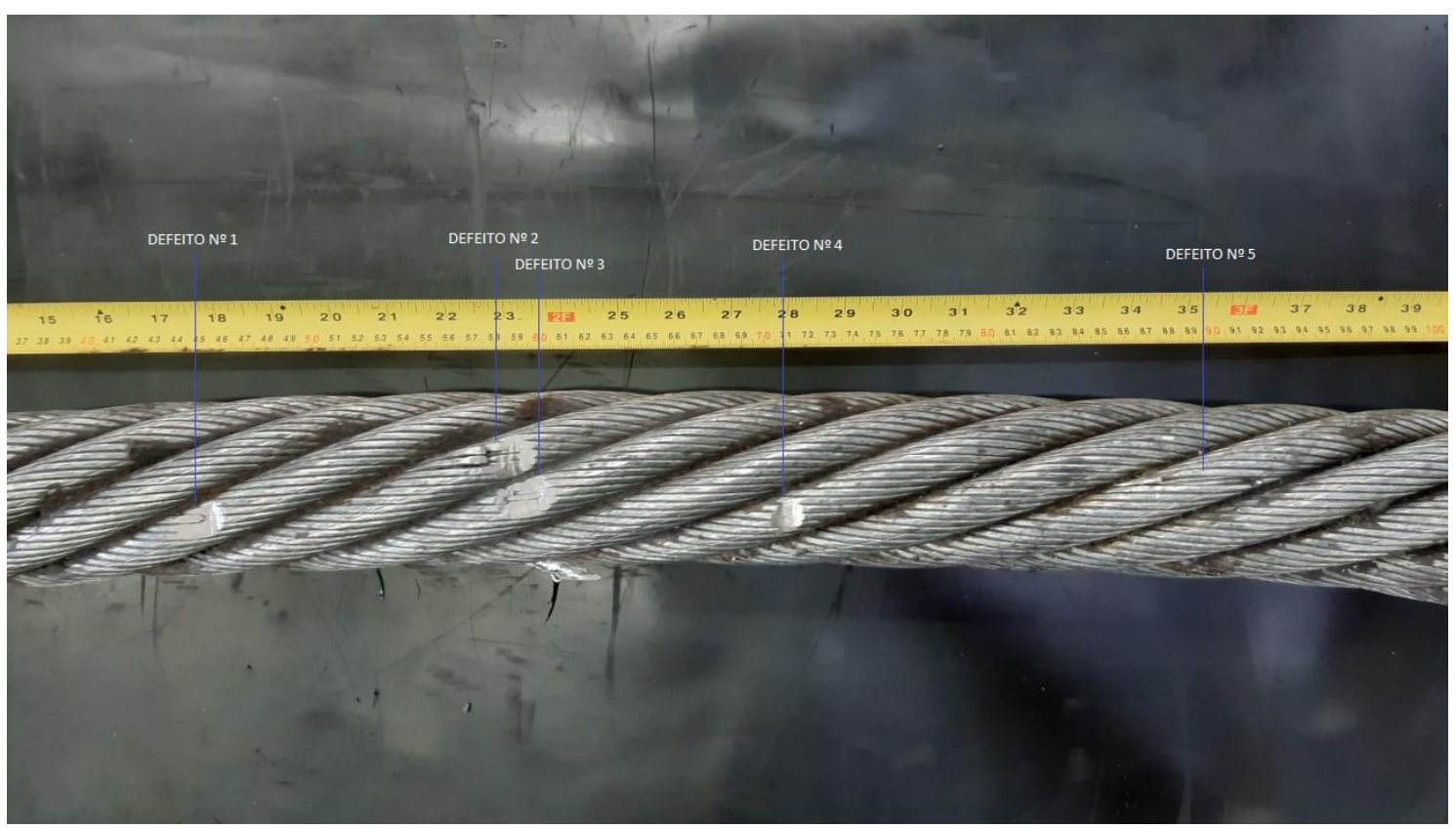

Fonte: Próprio Autor; (2020).

A figura 4 mostra o corpo de prova 1, aonde foram usinados defeitos no padrão de perda de área metálica por corrosão e a subtração de uma grande seção de arames da perna do cabo de aço no defeito 5. A tabela 1 mostra as dimensões de cada um dos cinco defeitos para esses padrões de defeitos. 
Tabela 1: Dimensões dos defeitos de perda de área metálica devido a corrosão.

\begin{tabular}{|c|c|c|c|}
\hline \multicolumn{4}{|c|}{ Corpo de prova 1 } \\
\hline \multicolumn{4}{|c|}{ Comprimento: 1055 mm } \\
\hline \multicolumn{2}{|c|}{$\begin{array}{c}\text { Padrão de defeitos: Perda de área metálica por corrosão (LMA) e perda de } \\
\text { seço de arames }\end{array}$} \\
\hline (LMA) & Comprimento & Largura/abertura & Profundidade \\
\hline Defeito 1 & $21 \mathrm{~mm}$ & $12 \mathrm{~mm}$ & $3 \mathrm{~mm}$ \\
\hline Defeito 2 & $25 \mathrm{~mm}$ & $16 \mathrm{~mm}$ & $4 \mathrm{~mm}$ \\
\hline Defeito 3 & $25,7 \mathrm{~mm}$ & $14,2 \mathrm{~mm}$ & $4,2 \mathrm{~mm}$ \\
\hline Defeito 4 & $15,2 \mathrm{~mm}$ & $13,4 \mathrm{~mm}$ & $3 \mathrm{~mm}$ \\
\hline Defeito 5 & $40 \mathrm{~mm}$ & $3,4 \mathrm{~mm}$ & $7 \mathrm{~mm}$ \\
\hline
\end{tabular}

Fonte: Próprio Autor; (2020).

Esses defeitos mostrados na tabela 1 e simulados no corpo de prova, se caracterizam por uma perda de área metalica devido a corrosão desse elemento de máquina por star submetido a um ambiente agressivo no que se refere a corrosão, oxidação.

Figura 5: Gráfico com dados não tratados, defeito de corrosão.

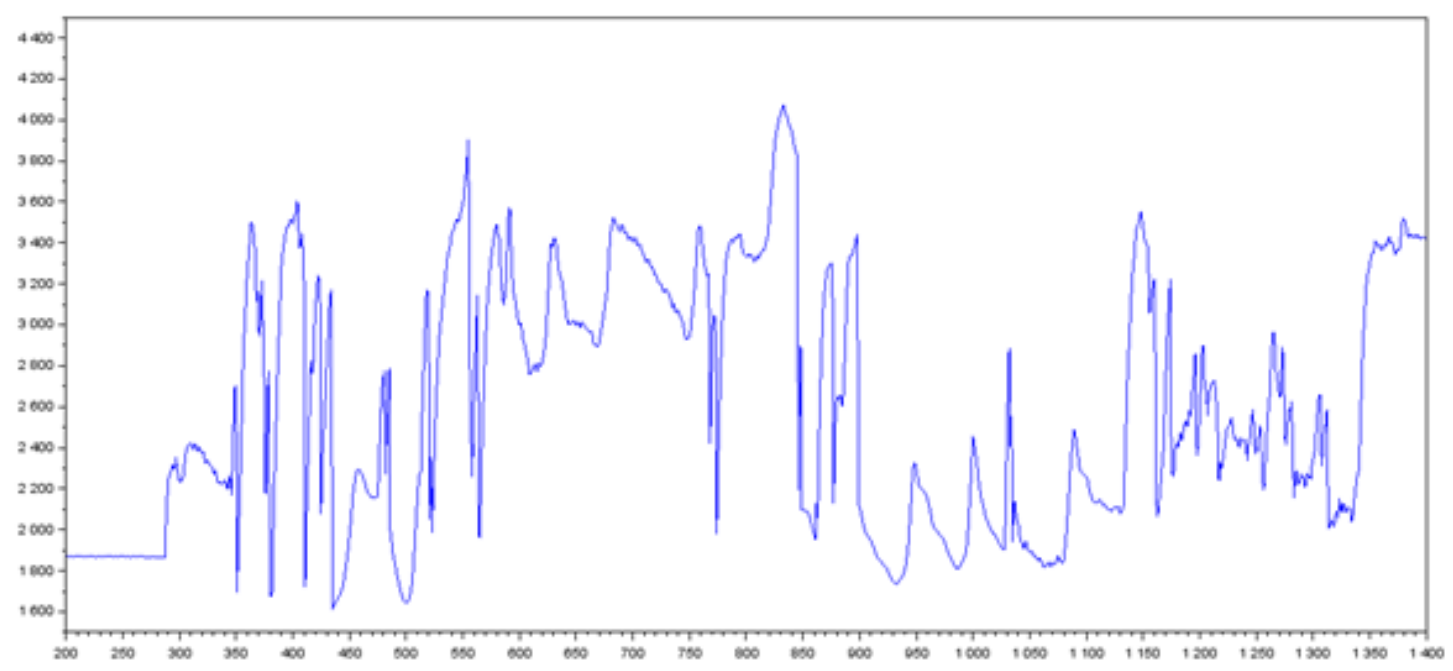

Fonte: Próprio Autor; (2020). 
A figura 5 mostra o gráfico para defeitos de perda de área metálica devido a corrosão no corpo de prova 1 . Importar dizer que, defeitos perda de área metálica manifestada por uma corrosão é difícil de ser identificado por essa técnica, salvo, quando a corrosão é muito severa. Na literatura são pouco os autores que tentaram essa identificação, porém, esse estudo apresentou resultados promissores mesmo o ruído da geometria do cabo de aço ter apresentado valores próximos aos visualizados na região de defeito.

Figura 6: Gráfico com dados tratados, defeitos de corrosão.

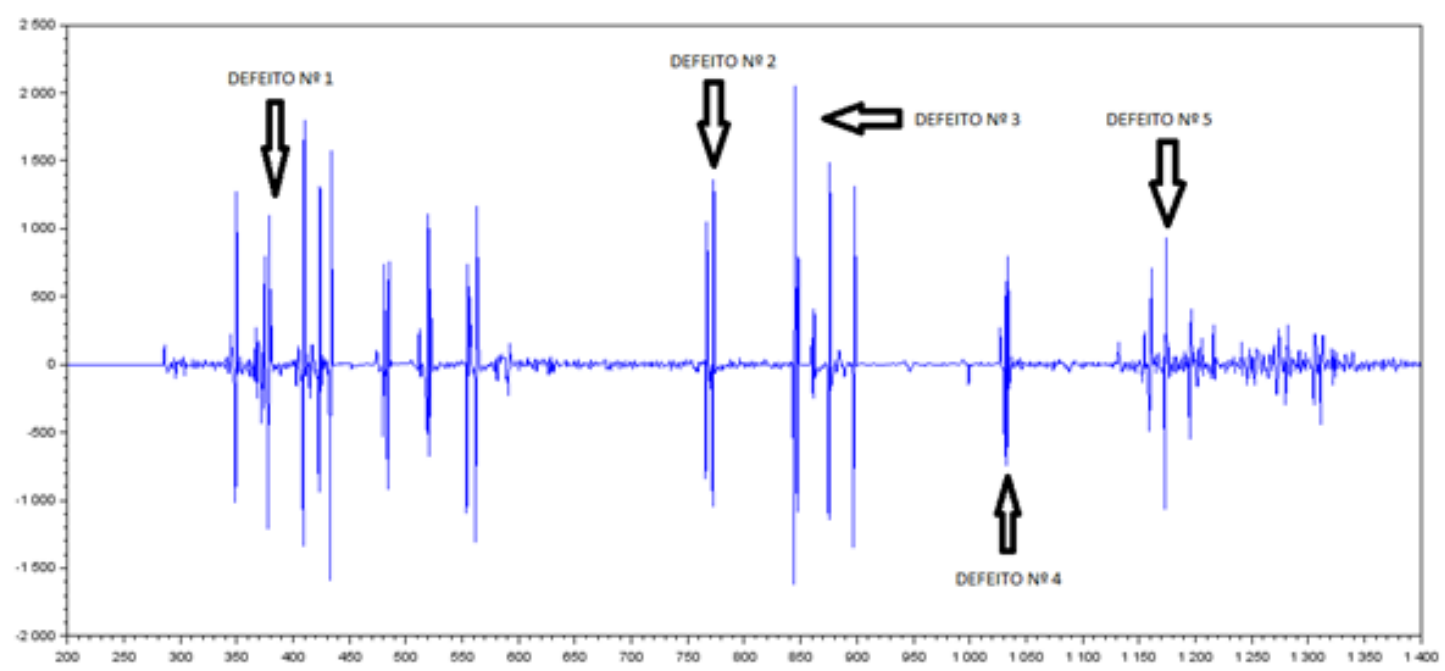

Fonte: Próprio Autor; (2020)

Utilizando o método de ensaio já mencionado anteriormente e contando com o auxílio do SciLab ao tratar os dados a partir da derivada dentro dos limites para o sinal sem defeito do material, a figura 6 mostram os resultados para os defeitos de perda de área metálica devido a corrosão. 
Figura 7: Corpo de prova 1, defeitos de entalhe.

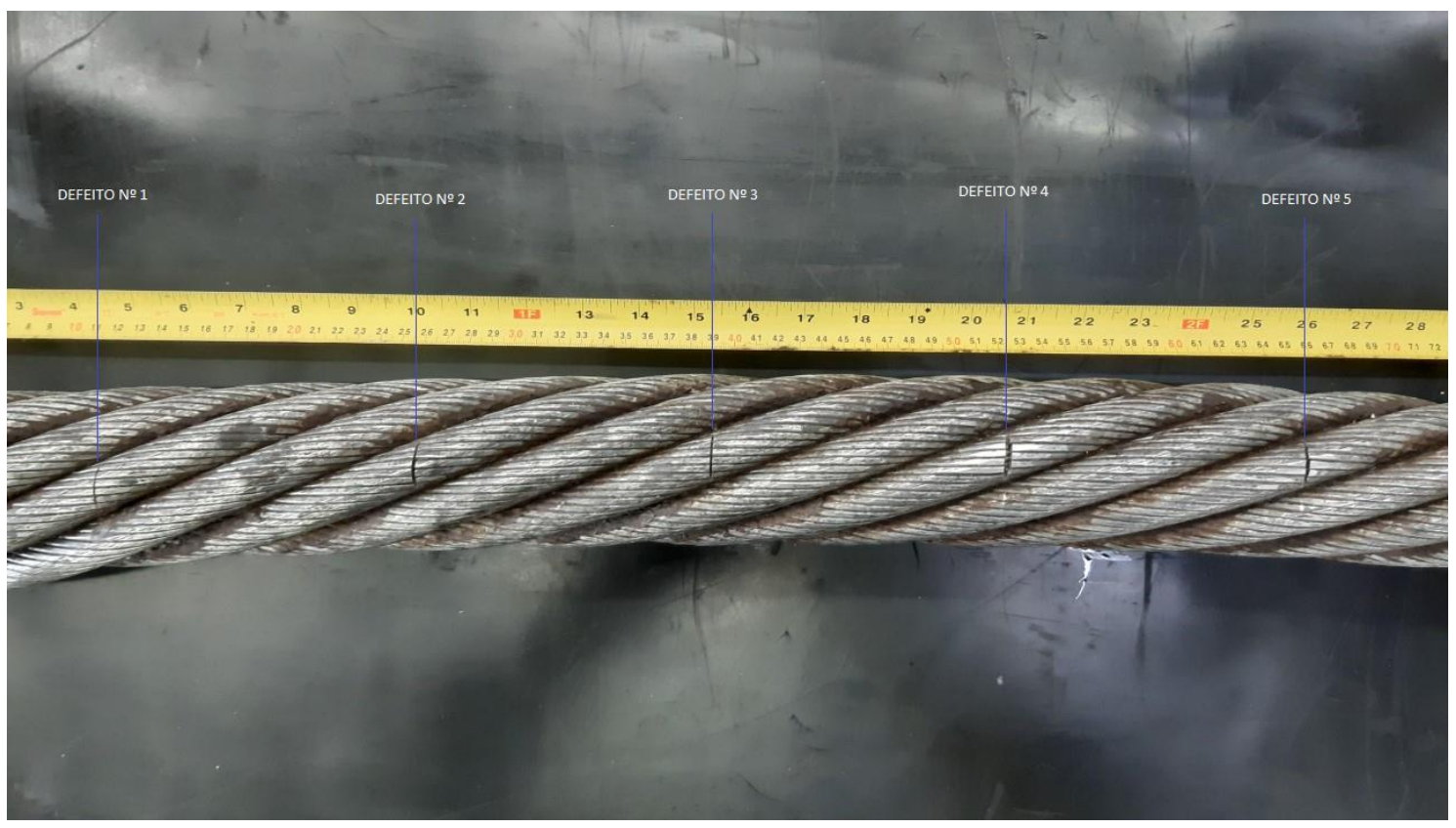

Fonte: Próprio Autor; (2020)

Ainda ao falarmos do corpo de prova 1, nota-se, pela figura 7, a presença de 5 defeitos usinados na geratriz oposta a dos defeitos de corrosão. Esses foram produzidos na intenção de simular o defeito de entalhe nos arames do cabo de aço que, porém, não rompem totalmente a estrutura desse arame.

Tabela 2: Dimensões para defeito de entalhe, corpo de prova 1.

\begin{tabular}{|l|l|l|l|}
\hline \multicolumn{4}{|c|}{ Corpo de prova 1 } \\
\hline \multicolumn{4}{|c|}{ Comprimento: 1055 mm } \\
\hline \multicolumn{3}{|c|}{ Padrão de defeitos: Entalhe dos arames (LF) na perna do cabo de aço } \\
\hline Comprimento & Largura/abertura & Profundidade \\
\hline Defeito 1 & $18 \mathrm{~mm}$ & $0,8 \mathrm{~mm}$ & $1,8 \mathrm{~mm}$ \\
\hline Defeito 2 & $18,55 \mathrm{~mm}$ & $1,7 \mathrm{~mm}$ & $2,5 \mathrm{~mm}$ \\
\hline Defeito 3 & $18,75 \mathrm{~mm}$ & $1,3 \mathrm{~mm}$ & $2 \mathrm{~mm}$ \\
\hline Defeito 4 & $19,2 \mathrm{~mm}$ & $3 \mathrm{~mm}$ & $3,3 \mathrm{~mm}$ \\
\hline Defeito 5 & $18,9 \mathrm{~mm}$ & $2 \mathrm{~mm}$ & $2,9 \mathrm{~mm}$ \\
\hline
\end{tabular}

Fonte: Próprio Autor; (2020) 
A tabela 2 mostra as dimensões de cada um dos cinco defeitos simulados nos arames da perna do cabo de aço. Em trabalhos futuros tem-se a intenção de criar uma metodologia para relacionar o grau de profundidade do defeito com a amplitude do sinal de tensão de hall, ou seja, para determinada calibração, se no gráfico, quando do momento da inspeção, apresentar um valor $\mathrm{X}$, relacionar esse valor de $\mathrm{X}$ diretamente com o valor nominal da profundidade em milimetros.

Figura 8: Dados não tratados para defeitos de entalhe.

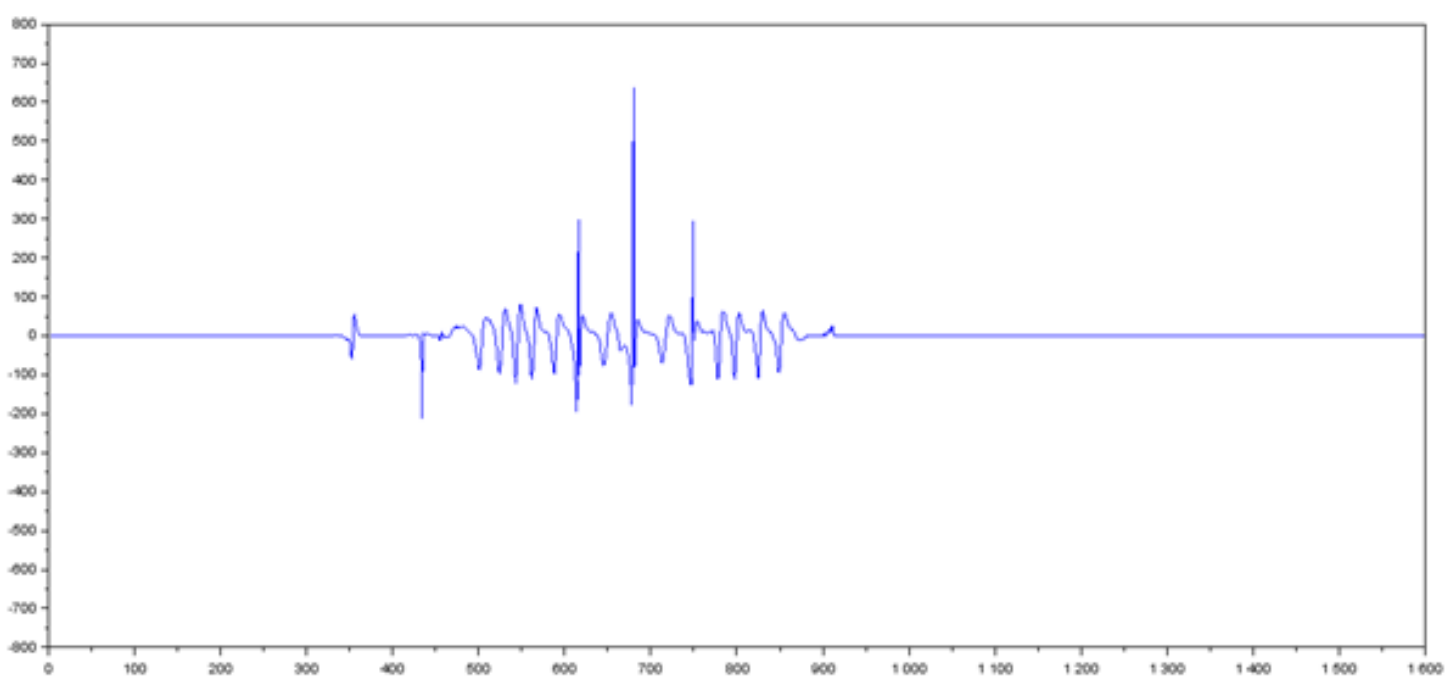

Fonte: Próprio Autor; (2020)

Defeitos de entalhe nas pernas do cabo de aço, tem-se mostrada como defeitos mais fáceis de serem identificados. Em muitos testes de corrida do sensor, o sinal do gráfico se mostra tão bom, que muita da vezes dispensa o tratamento de dados como mostra a figura 8 . 
Figura 9: Dados tratados para defeitos de entalhe.

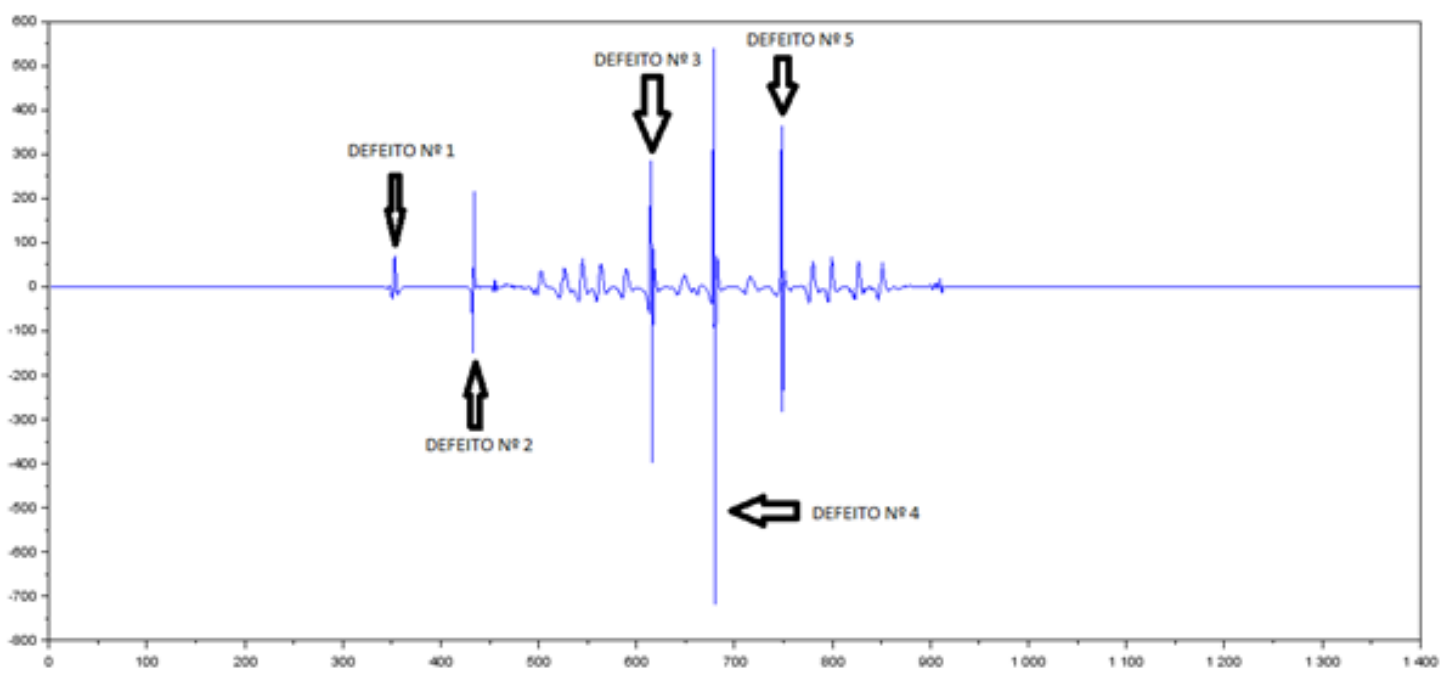

Fonte: Próprio Autor; (2020)

Por se tratar de um defeito que é mais flagrante se comparado ao defeito de corrosão, o tratamento de dados para esse defeito é mais facilitado. Não há muito diferença entre o sinal tratado e o sinal não tratados.

Figura 10: Defeitos de rompimentos de arames na perna do cabo de aço, corpo de prova 2.

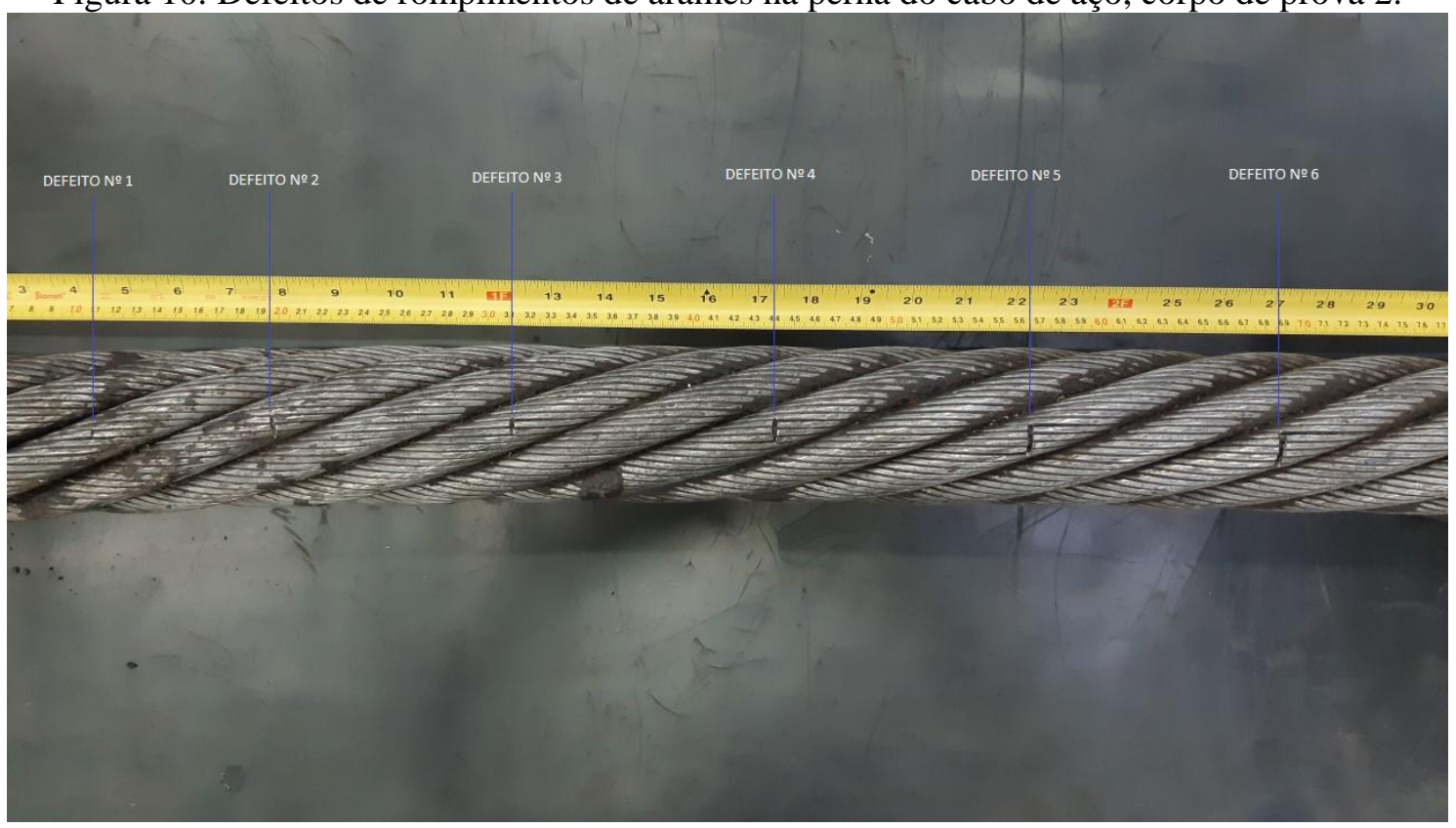

Fonte: Próprio Autor; (2020) 
O corpo de prova 2 nos revela, tão só e simplesmente, defeitos em um geratriz. Esses defeitos simulam níveis de rompimento dos arames, os quais, há uma total ruptura dos arames do cabo de aço. A figura 10 diferentes quantidades de arames rompidos nas pernas do cabo.

Tabela 3: Dimensões para defeitos de rompimento de arames.

\begin{tabular}{|l|l|l|l|l|}
\hline \multicolumn{5}{|c|}{ Corpo de prova 2 } \\
\hline \multicolumn{5}{|c|}{ Comprimento: 1005 mm } \\
\hline Padrão de defeitos: Níveis de rompimento de arames (LF) na perna do cabo de \\
\hline aço
\end{tabular}

Fonte: Próprio Autor; (2020)

A tabela 3 mostra as dimensões dos defeitos para níveis de rompimento de arames, evidenciando a quantidade de arames rompidos em cada um dos defeitos. Na realidade o que define os defeitos são principalmente a quantidade de arames rompidos por perna. 
Figura 11: Dados não tratados para os de defeitos de rompimento de arames.

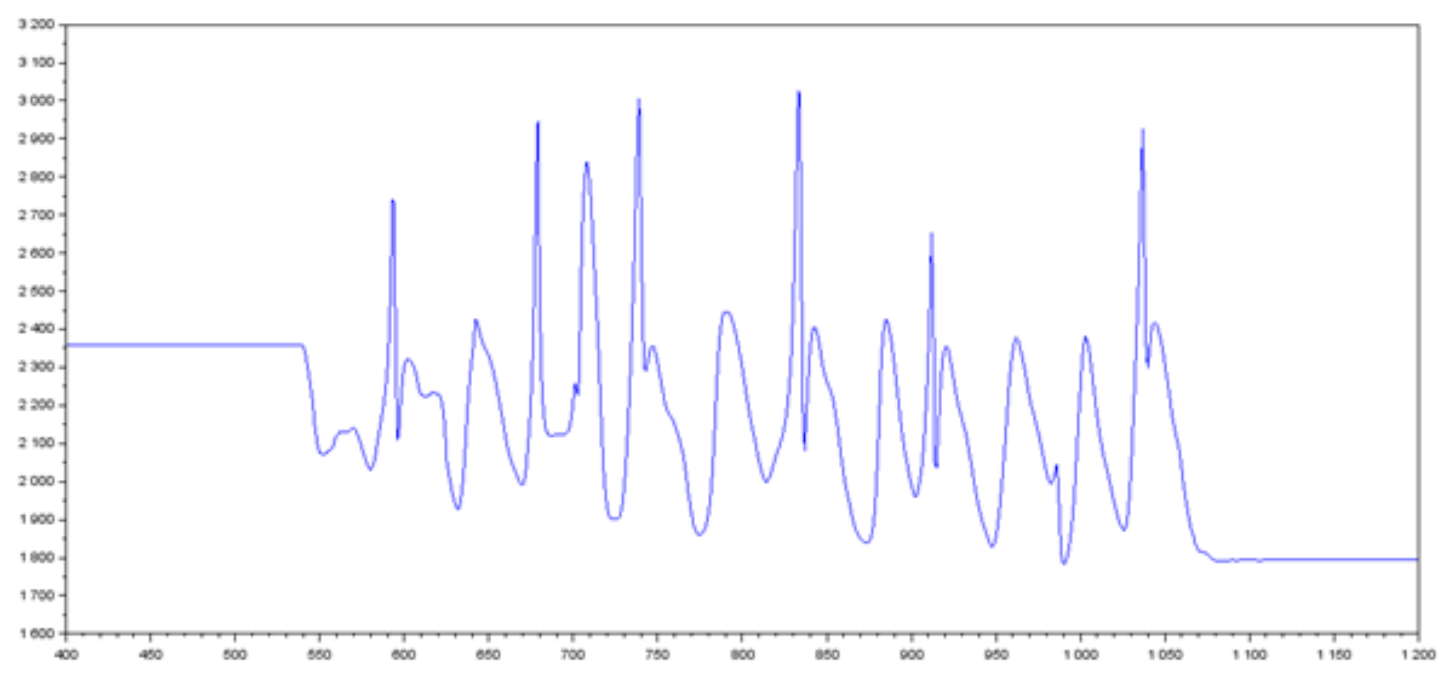

Fonte: Próprio Autor; (2020)

Por se tratar de um defeito aonde há a total ruptura dos arames, esse defeito também se caracteriza pela fácil identificação e, consequentemente, a clara diferença entre os valores de tensão que representam a geometria do cabo de aço, para os valores de tensão que representa os defeitos de rompimento do arame da perna do cabo de aço como mostra a figura 11.

Figura 12: Dados tratados para defeitos de rompimento de arames na perna do cabo de aço.

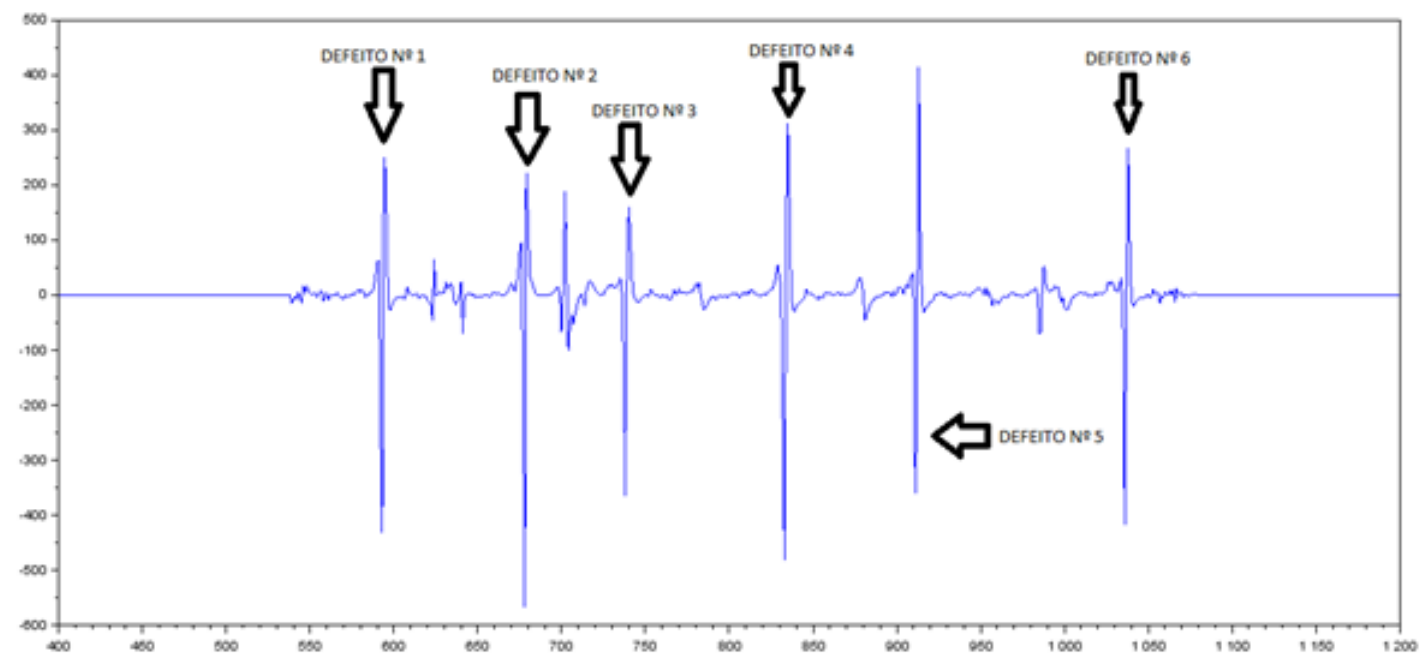

Fonte: Próprio Autor; (2020)

Utilizando-se da técnica de tratamento de dados a partir do programa de 
computação numérica SciLab, chegou-se a esse refino no tratamento do sinal de tensão para os defeitos de rompimento dos arames. Técnica de derivação dentro dos limites propostos revelou-se eficiente no transparecer desses defeitos como mostra a figura 12.

\section{DESENHO DA FERRAMENTA DE INSPEÇÃO A PARTIR DO PROJETO MECÂNICO CONCEITUAL AO SE UTILIZAR O SOLIDWORKS.}

Esse estudo também prevê a realização de um projeto mecânico conceitual que vai carregar todos os conceitos estudados até aqui com a finalidade de desenvolver uma ferramenta apta a inspecionar cabos de aço que se usa em linhas de ancoragem de plataformas semissubmersíveis e também que se utiliza em outras atividades na indústria de petróleo offshore. Considerando vários aspectos em projeto, chegou ao seguinte conceito de ferramenta mostrada nas figuras 13,14 e 15.

Figura 13: Um dos vinte sensores usados na ferramenta conceitual.

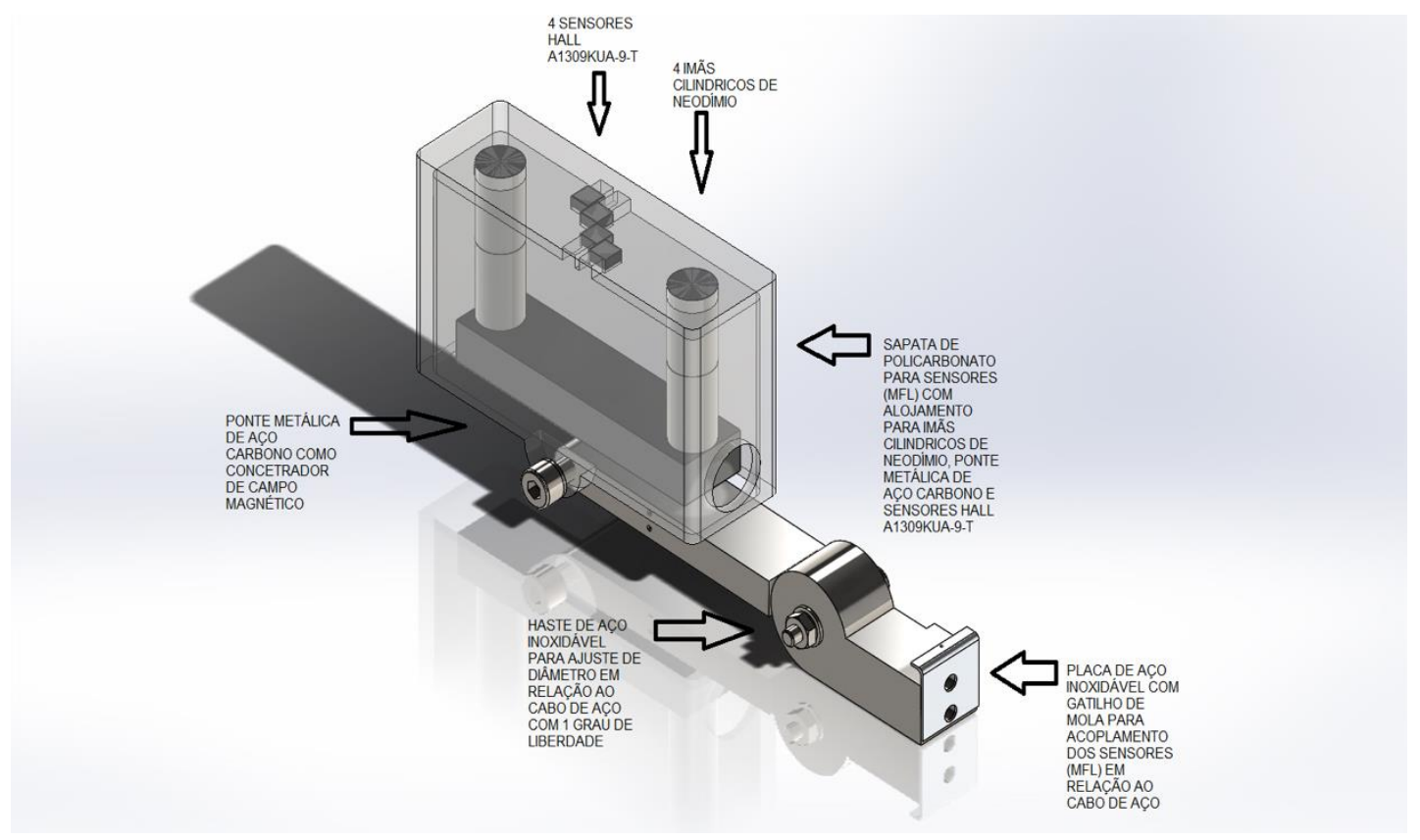

Fonte: Próprio Autor; (2020).

Vários aspectos foram levados em consideração dentro desse projeto mecânico conceitual, dentre os quais, a utilização de 20 sensores como o que se mostra na figura 13. Soma-se a isso, a utilização de 4 elementos sensores (sensor hall) em cada sensor com a intenção de eliminar as áreas mortas, que são área aonde pode-se um falso negativo em relação a presença de defeito por conta da falta de um elemento sensor quando da passagem do sensor ao se transladar a ferramenta ao longo da superfície do cabo de aço. 
Figura 14: Ferramenta de inspeção conceitual.

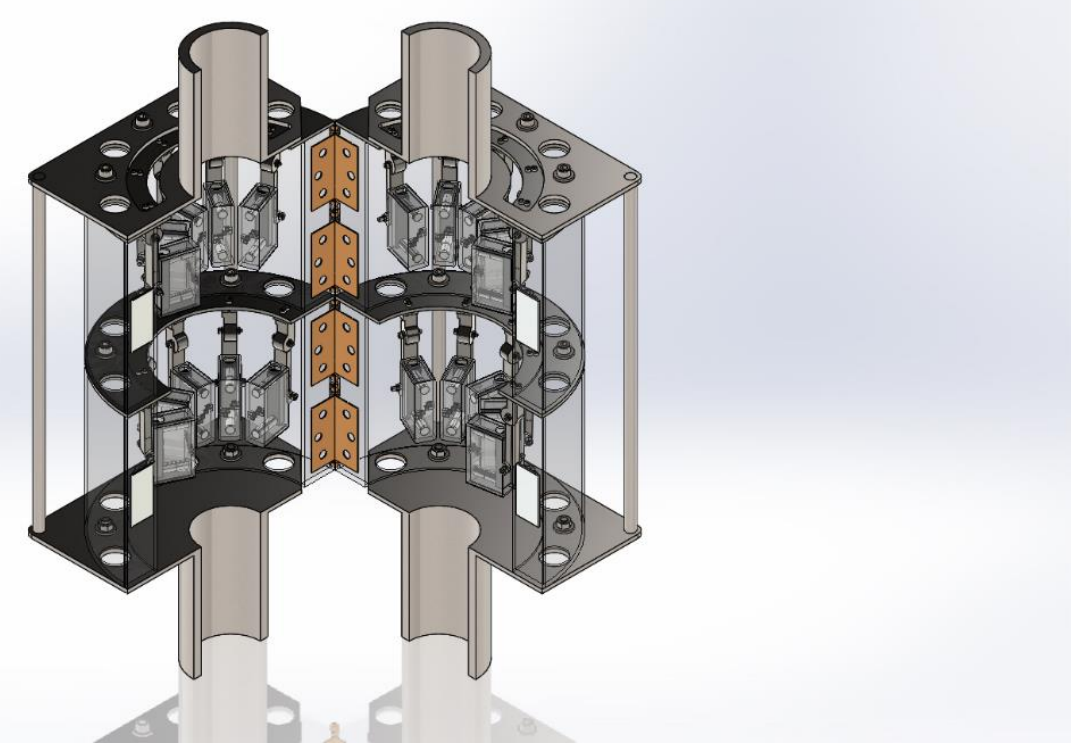

Fonte: Próprio Autor; (2020)

Na figura 14, a ferramenta de inspeção tem um conceito de dobradiças para facilitar o acesso ao cabo de aço em qualquer das duas extremidades, pois a realização da inspeção se dará com o cabo de aço em utilização. As barras laterais tem a função de auxiliar na tração da ferramenta por um veículo submarino operado remotamente, mais conhecido como ROV.

Figura 15: Interação entre o cabo de aço e a ferramenta conceitual.

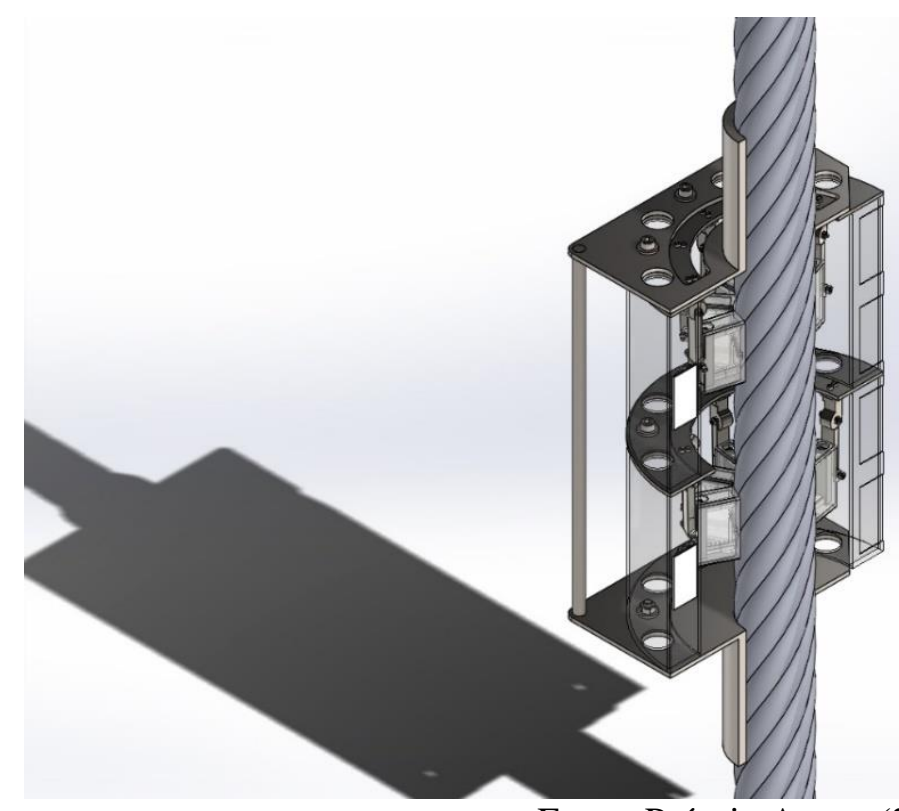

Fonte: Próprio Autor; (2020). 
A figura 15 mostra como se dará a interação entre a ferramenta de inspeção e o cabo de aço. Percebe-se que os 20 sensores acompanham a superfície do cabo de aço, totalizando 80 canais de sensoriamento por conter 4 sensores hall em cada sapata do sensor como fora mencionado anteriormente.

\section{CONCLUSÃO}

A partir de todo o referencial teórico reunido e contando com inúmeros testes laboratoriais foi possível se chegar a resultados que comprovam a eficácia da técnica de inspeção eletromagnética que se baseia no vazamento de fluxo magnético, a partir da análise de resultados expostos neste estudo para os defeitos localizados de entalhe e rompimento de arames em pernas de cabos de aço.

Importante salientar que os defeitos de perda de área metálica por corrosão requerem um estudo mais aprofundado para que se possa dizer com toda certeza que os sinais de amplitude de tensão em gráficos para esse tipo de defeitos são seguros num teste em campo.

Precisa-se alcançar uma amplitude de sinal de tensão que diferencie o sinal de defeito em relação ao sinal da geometria do cabo de aço no que diz respeito aos defeitos de perda de área metálica devido a corrosão.

Importante dizer, que todo esse conhecimento teórico aliado aos testes de inspeção e o desenvolvimento de um projeto mecânico conceitual capaz de carregar todo um ferramental indispensável para futuros testes dentro de uma plataforma semissubmersível offshore que trabalha com linhas de ancoragem a partir de cabos de aço tem o potencial para atingir os objetivos iniciais nesse estudo.

O objetivo era detectar descontinuidades em arames, arames rompidos e perda de área metálica devido a corrosão, os resultados comprovaram que esses defeitos são suscetíveis a inspeção da qual foram alvo e corrobora toda uma teoria em volta desse estudo.

\section{REFERENCIAS}

ABNT NBR 16073 Ensaios não destrutivos - Inspeção eletromagnética - Cabos de aço ferromagnéticos. 
BRAGA, Newton C. "Como funcionam os sensores de Efeito Hall”. Disponível em: < https://www.newtoncbraga.com.br/index.php/como-funciona/6640-como-funcionam-ossensores-de-efeito-hall-art1050 > .

PETROBRAS. Pré-sal. Desde as primeiras descobertas em águas profundas, temos trilhado uma longa jornada tecnológica. Disponível em: < https://petrobras.com.br/pt/nossas-atividades/areas-de-atuacao/exploracao-e-producaode-petroleo-e-gas/pre-sal/ >.

PETROBRAS. Tipos de plataformas. Disponível em: < https://petrobras.com.br/infograficos/tipos-de-plataformas/desktop/index.html >.

UNIVERSIDADE FEDERAL DE JUIZ DE FORA. Departamento de Física - Instituto de Ciências Exatas. "O efeito hall”. Disponível em: < https://www.ufjf.br/fisica/files/2013/10/FIII-06-07-O-efeito-Hall.pdf >.

ZHANG, Yiqing et al. A Sensor for Broken Wire Detection of Steel Wire Ropes Based on the Magnetic Concentrating Principle. 2019. Disponível em: < https://europepmc.org/backend/ptpmcrender.fcgi?accid=PMC6749426\&blobtype =pdf $>$.

\section{Recebido em: 01/06/2021}

Aprovado em: 20/06/2021 